\title{
Knowledge, attitude and practice of Ethiopian pediatricians concerning childhood eye diseases
}

\author{
Tolosa Tufa Regassa ${ }^{1 *}$ D, Kumale Tolesa Daba ${ }^{1}$, Ido Didi Fabian² and Aemero Abateneh Mengasha ${ }^{1}$
}

\begin{abstract}
Background: Eye examination and vision assessment are vital for the detection of conditions that result in blindness. Childhood blindness seriously impacts the development, education, and future employment opportunities of affected children. Pediatricians' knowledge of eye diseases is critical for the prevention of blindness through early diagnosis, allowing proper treatment and identification of conditions requiring referral to an ophthalmologist to preserve or restore vision. This study aimed to assess the knowledge, attitude, and practice of Ethiopian pediatricians concerning childhood eye diseases.

Methods: We carried out a cross-sectional descriptive study of pediatricians working in various hospitals and clinics in Ethiopia. Participants were selected via a convenient sampling technique. Data were collected using both closed and open-ended semi-structured questionnaires. Responses were entered into EpiData 3.1 and transferred to SPSS version 21.0 software for analysis.
\end{abstract}

Results: A total of 79 pediatricians participated in the study. Our findings showed that the attitude of all but 2 participants towards improving the management of childhood eye diseases was positive, even though this was not reflected in actual knowledge or practice. Even though attitudes were positive, knowledge was often poor and practice inadequate owing to barriers such as inadequate undergraduate training, lack of ophthalmology options during pediatric residency, and unavailability of ophthalmic equipment.

Conclusions: Participants' attitudes towards improving treatment for childhood eye diseases are positive, but their insufficient knowledge of eye diseases makes their practice poor in this respect.

Keywords: Knowledge, Attitude, Practice, Childhood blindness, Pediatrician, Jimma, Ethiopia

\section{Background}

Vision is critical for children's early development and is likely to provide a unifying mechanism through which information perceived through other sensory modalities can be organized and become interrelated [1]. Early detection of visual impairment and providing correct and timely treatment is therefore imperative for the child's growth and development.

\footnotetext{
* Correspondence: tolasatu89@gmail.com

${ }^{1}$ Jimma University, Jimma, Ethiopia

Full list of author information is available at the end of the article
}

The global estimate of childhood blindness in 2015 was 1.14 million [2]. Causes of blindness in children vary widely between regions, reflecting socio-economic development, cultural practices, coverage of preventive measures (e.g. measles immunization), and access to appropriate eye care and optical services [3, 4]. Corneal scarring due to vitamin A deficiency, measles infection, ophthalmia neonatorum, and the harmful effects of traditional eye remedies are the most common causes of visual impairment in many low-income countries, whereas in high-income countries the main causes are cortical

C C The Author(s). 2021 Open Access This article is licensed under a Creative Commons Attribution 4.0 International License, which permits use, sharing, adaptation, distribution and reproduction in any medium or format, as long as you give appropriate credit to the original author(s) and the source, provide a link to the Creative Commons licence, and indicate if changes were made. The images or other third party material in this article are included in the article's Creative Commons licence, unless indicated otherwise in a credit line to the material. If material is not included in the article's Creative Commons licence and your intended use is not permitted by statutory regulation or exceeds the permitted use, you will need to obtain permission directly from the copyright holder. To view a copy of this licence, visit http://creativecommons.org/licenses/by/4.0/ The Creative Commons Public Domain Dedication waiver (http://creativecommons.org/publicdomain/zero/1.0/) applies to the data made available in this article, unless otherwise stated in a credit line to the data. 
visual impairment, retinal disorders including retinopathy of prematurity (ROP) and disorders of the optic nerve. ROP is a major cause of visual impairment in children in middle-income countries and in urban centers of low-income countries [4-8].

A blind child is more likely to be living under conditions of socioeconomic deprivation, to be more frequently hospitalized during childhood, and to die in childhood than a child not living with blindness. About two-thirds of blind children live in developing countries, and up to $60 \%$ of these children who become blind because of keratomalacia are likely to die within 1 year of becoming blind $[9,10]$.

In Ethiopia, eye problems are among the major public health challenges, with huge economic and social impacts on affected individuals and the society, and the nation at large. Childhood blindness accounts for over 6\% of the total blindness burden in this country. Sightthreatening or life-threatening ocular disorders such as congenital cataracts, corneal blindness (mainly as a result of measles and vitamin A deficiency), congenital eye anomalies, retinoblastoma, and glaucoma are common ocular morbidities in Ethiopia [11, 12]. Many of these could be either prevented or treated by early diagnosis and treatment. Pediatricians can play an important part in preventing blindness in children through routine screening of vision at well-child visits. However, early detection and appropriate referral to an ophthalmologist are largely dependent on the pediatrician's knowledge, attitude, and practice (KAP).

In a questionnaire-based study carried out in the USA in 2012 to assess practices, attitudes, and perceived barriers among pediatricians to pediatric vision screening, Couser et al. [13] reported that in Atlanta, GA, USA, the majority of respondents (67\%) indicated that they did not begin formal visual acuity (VA) testing until children were at least 3 years old. The most frequently reported barriers to screening were inadequate training (48\%) and time required for examination (42\%) [13]. In a survey carried out in 1995 in Illinois, USA, to determine statewide compliance with the requirement of vision screening by pediatricians, Marcinak et al. [13] reported that $60 \%$ of pediatricians tested the VA of children aged 5 years and older, and that half of these pediatricians also tested children aged 2 to 4 . The commonest reasons given by those pediatricians for not testing VA were inadequate time $(42 \%)$, children too young $(18 \%)$, or that screening would be done at school (18\%) [14]. In a national sample of pediatricians surveyed to evaluate preschool vision screening practices, Kemper and Clark [15] found that the rate of VA screening in 3-year-old children was low (35\%) but was increased in children aged 4 (73\%) and 5 (66\%). Commonly reported barriers to vision screening were that screening was too time- consuming (49\%) and children were uncooperative (23\%). A few pediatricians (3\%) in that survey affirmed that screening was unnecessary because vision problems would be identified elsewhere (e.g., by the family) [14]. In a study by Wanyama et al. of the KAP of eye diseases in children among pediatricians in Kenya [16], knowledge was poor in $69.6 \%$ of the 125 study respondents. Of the $69.6 \%$ of participants in that study who reported carrying out eye examinations in children, only $43.5 \%$ did so as a routine part of every child's examination. Among the $30.4 \%$ who reported not doing eye examination, the reasons given were insufficient time to do the examination (39.5\%) and not knowing how to do it (31.6\%) [15].

In Ethiopia, the distribution of ophthalmologists and eye-care workers in the various regions of the country is currently inadequate compared to that of pediatricians. Despite the prominent role of pediatricians in the prevention of childhood blindness, their KAPs concerning childhood eye diseases are not known. The present study was therefore undertaken to assess the KAPs of Ethiopian pediatricians concerning childhood ocular morbidities.

\section{Methods}

The study population of this cross-sectional descriptive study comprised 79 pediatricians who work in various hospitals and clinics in Ethiopia. Following ethical clearance obtained from the Ethical Review Committee of Jimma University, participants were recruited for the study by convenience sampling during the annual conference of the Ethiopian Pediatric Society held in February 2019. After being informed about the study, the questionnaire developed for this study (provided as Additional file 1), each participant was required to sign a written consent form before completing a closed- and open-ended self-administered structured questionnaire. These were distributed on tables in the conference room and were later collected by two well-oriented ophthalmic nurses and one optometrist. Only those pediatricians who had signed their informed consent were included in the study population. The collected data were checked for completeness and were then coded, entered into EpiData version 3.1, and exported to SPSS version 21. Descriptive statistics were expressed as frequency, percentage, mean, range, and standard deviation. The overall KAP of each participant was analyzed in detail and presented in tabular form. A Chi-square test was used to test the associations between different variables, and a $P$-value of $<0.05$ was interpreted as statistically significant.

Participants' knowledge and practice were categorized according to Bloom's cut-off points into 'good' $(>80 \%)$, 'moderate' (60-80\%), or 'poor' $(<60 \%)$ [16]. Their 
responses in the part of the questionnaire assessing attitudes to childhood eye diseases were categorized as positive or negative statements on the Likert scale. Scores in that section varied from 11 to 55 , and all individual answers by each participant were summed to obtain his or her total score, which was then classified into 1 of 3 attitude levels: 'positive' (scores of 44 to 55 were equivalent to $80 \%-100 \%$ ); 'neutral' (scores of 33 to 43 , equivalent to $60 \%-80$ ), and 'negative' (scores $<33$, equivalent to less than $60 \%$ ).

The following operational definitions were used: Children: age $<16$ (UNICEF); Knowledge: what eye diseases the pediatrician is familiar with in children; Attitude: how pediatricians feel and what they believe concerning eye disease in children; Practice: actions the pediatrician intends to take to prevent blindness in children.

\section{Results}

\section{Background characteristics of participants}

Questionnaires were completed and returned by 79 of the 123 eligible pediatricians who were attending the conference, a response rate of $64.2 \%$. The respondents comprised 45 males and 34 females. Their mean age was
37.8 years $(\mathrm{SD}=9.8$ years), range $26-66$ years, and their mean duration of medical practice was 8.2 years, range $1-33$ years (Table 1$)$.

\section{Knowledge of childhood eye diseases}

Knowledge of the 79 pediatricians about childhood diseases, as reflected by their responses on the questionnaire, is indicated in Table 2. As recorded in the table, the large majority 63; $779.3 \%$ ) of respondents (Table 2) did not know signs of poor vision in children, and the rest had only poor knowledge of such signs, with 'poor school performance' being the one most frequently recognized. Only a few knew the definition of blindness according to the World Health Organization (WHO). There was good overall awareness of more than one ocular sign of vitamin A deficiency, the most frequently recognized signs being Bitot's spots, xerosis, and keratomalacia.

As also shown in Table 2, all but 3 of the 79 pediatricians knew that refractive error is correctable. Most of those responded that it can be corrected by spectacles, with smaller numbers indicating that it can be corrected by the use of contact lenses or by surgery. There was a

Table 1 Background characteristics of participants $(n=79)$

\begin{tabular}{|c|c|c|}
\hline Characteristics & Variables & n (\%) \\
\hline \multirow[t]{2}{*}{ Sex } & Female & $34(43.0)$ \\
\hline & Male & $45(57.0)$ \\
\hline \multirow[t]{4}{*}{ Age (years) } & $21-30$ & $27(34.2)$ \\
\hline & $31-40$ & $24(30.4)$ \\
\hline & $41-50$ & $26(32.9)$ \\
\hline & $51-60$ & $2(2.5)$ \\
\hline \multirow[t]{4}{*}{ Duration of practice (years) } & $1-10$ & $54(68.4)$ \\
\hline & $11-20$ & $20(25.3)$ \\
\hline & $21-30$ & $1(1.3)$ \\
\hline & $>30$ & $>4(5.1)$ \\
\hline \multirow[t]{3}{*}{ Type of practice } & Government & $57(72.2)$ \\
\hline & Private & $17(21.5)$ \\
\hline & Non-governmental organization (NGO) & $5(6.3)$ \\
\hline \multirow[t]{3}{*}{ Place of practice } & Specialist hospital & $56(70.9)$ \\
\hline & General hospital & $20(25.3)$ \\
\hline & Primary hospital & $3(3.8)$ \\
\hline \multirow[t]{6}{*}{ Duration of undergraduate training in ophthalmology ${ }^{\mathrm{a}}$ (weeks) } & 2 & $25(31.6)$ \\
\hline & 3 & $15(19.0)$ \\
\hline & 4 & $17(21.5)$ \\
\hline & 5 & $8(10.0)$ \\
\hline & 6 & $12(15.2)$ \\
\hline & Not sure & $2(2.5)$ \\
\hline Duration of postgraduate training in ophthalmology (weeks) & 2 & $2(2.5)$ \\
\hline
\end{tabular}

andergraduate ophthalmology training at a medical school in Ethiopia 
Table 2 Knowledge of pediatricians about childhood eye diseases

\section{Characteristic}

Do you know of any signs of poor vision in children?

Knowledge of WHO definition of blindness

Knowledge of ocular signs of vitamin A deficiency

Knowledge of causes of leukocoria in children

When to refer a child with leukocoria?

Is refractive error correctable?

Ways of refractive error correction

Systemic illnesses in children associated with congenital cataracts

Do you know about retinopathy of prematurity?

What is the age to screen for retinopathy of prematurity?

Knowledge about presentation of congenital glaucoma

Knowledge about complication of squint in children

Knowledge of causes of tearing in infant

\begin{tabular}{|c|c|}
\hline Variable & n (\%) \\
\hline No & $63(79.8)$ \\
\hline Yes & $16(20.3)$ \\
\hline Poor school performance & $12(15.2)$ \\
\hline Nystagmus & $2(2.5)$ \\
\hline Frequent eye rubbing or blinking & $1(1.3)$ \\
\hline Head tilted to one side & $1(1.3)$ \\
\hline$V A<3 / 60$ & $25(31.6)$ \\
\hline No light perception & $20(25.3)$ \\
\hline Don't know & $22(27.8)$ \\
\hline$V A<6 / 60$, but $\geq 3 / 60$ & $12(15.2)$ \\
\hline Bitot's spots & $66(83.5)$ \\
\hline Ocular xerosis & $63(79.7)$ \\
\hline Keratomalacia & $63(79.7)$ \\
\hline Night blindness & $19(24.1)$ \\
\hline Retinoblastoma & $76(96.2)$ \\
\hline Cataract & $57(72.2)$ \\
\hline Retinopathy of prematurity & $40(50.6)$ \\
\hline Retinal detachment & $17(21.5)$ \\
\hline Immediately & $79(100)$ \\
\hline Yes & $76(96.2)$ \\
\hline Don't know & $3(3.8)$ \\
\hline Spectacles & $65(82.3)$ \\
\hline Surgery & $39(49.4)$ \\
\hline Contact lens & $38(48.1)$ \\
\hline TORCH syndrome & $74(93.7)$ \\
\hline Metabolic disorder & $20(25.3)$ \\
\hline Don't know & $2(2.5)$ \\
\hline Yes & $77(97.5)$ \\
\hline No & $2(2.5)$ \\
\hline 4-6 weeks & $67(84.8)$ \\
\hline Don't know & $7(8.9)$ \\
\hline $6-12$ months & $5(6.3)$ \\
\hline Skipped the question & $55(69.6)$ \\
\hline Buphthalmos(enlarged eye) & $14(17.7)$ \\
\hline Lacrimation & $13(16.5)$ \\
\hline Fear of light & $5(6.3)$ \\
\hline Loss of depth perception & $76(96.2)$ \\
\hline Lazy eye & $72(91.1)$ \\
\hline Social stigma & $46(58.2)$ \\
\hline Conjunctivitis & $55(69.6)$ \\
\hline Nasolacrimal duct obstruction & $46(58.3)$ \\
\hline Congenital glaucoma & $27(34.2)$ \\
\hline Skipped the question & $6(7.6)$ \\
\hline Foreign body & $1(1.3)$ \\
\hline
\end{tabular}


Table 2 Knowledge of pediatricians about childhood eye diseases (Continued)

\begin{tabular}{lll}
\hline Characteristic & Variable & $\mathbf{n}(\%)$ \\
\hline Knowledge about presenting signs of retinoblastoma & Leukocoria & $56(70.9)$ \\
$45(57.0)$ \\
$8(10.1)$ \\
$3(3.8)$ & Proptosis & Skipped the question \\
Treatment of retinoblastoma & Squint & 74 (93.7) \\
& Surgery & $70(88.6)$ \\
& Chemotherapy & 28 (35.4) \\
\hline
\end{tabular}

VA visual acuity

good knowledge of TORCH infection in children as a cause of cataract-associated systemic illness, but knowledge of the effects of other metabolic disorders was poor. All but 2 respondents knew about ROP, and most of them correctly said that the time to screen infants for ROP was at 4-6 weeks. Knowledge about the presenting features of congenital glaucoma was moderate to poor, as was recognition of conjunctivitis and/or nasolacrimal duct obstruction as causing tearing in infants.

Table 2 shows that in response to the question about presenting signs of retinoblastoma, more than half mentioned leukocoria, and a somewhat smaller number mentioned proptosis. For the treatment of retinoblastoma, 74 of the 79 of the respondents listed surgery and 70 listed chemotherapy.

All in all, the knowledge scores of the majority of respondents as shown in Table 2 were below $60 \%$, indicating that the overall level of knowledge of this study population was poor.

\section{Treatment practice and referral of eye disease cases}

Practices of the 79 pediatricians regarding treatment and referral of eye diseases in children are recorded in Table 3. To summarize those results, 68 responded that they do perform such eye examinations, but only 29 reported performing them routinely. More than half (59/ 79) perform a pupillary examination, and among those who do not, the most frequently cited reason was inadequate training. For children with red eyes, 5 reported an immediate referral for eye care. All the rest said that they prescribe eye drops; among these 74 responders, almost half said that failing improvement they refer the child for eye care, while a small number (6/74) said that following eye-drop administration they refer the child immediately. In the case of squint, the response of the large majority of responders was an immediate referral, while 5 said that they refer if the squint fails to resolve after follow-up. In the case of suspected retinoblastoma, most respondents listed immediate referral, while the remaining 20 reported ordering an imaging examination. For children with congenital cataracts or suspected congenital glaucoma, referral to eye-care workers was the response of nearly all of the pediatricians.

\section{Attitude of participants}

Table 4 shows that nearly all of the 79 responding pediatricians had a positive attitude to providing care in children with eye diseases.

\section{Discussion}

From the responses of the pediatricians who completed the questionnaire on which this study was based, it is evident from Table 2 that the large majority (63/79) had poor knowledge of the signs of poor vision in childrenalthough poor school performance, possibly a late sign of poor vision, was mentioned by an additional 12 responders. Those findings may be explained both by insufficient course time devoted to undergraduate ophthalmology, as the majority of participants had taken it for only 2 weeks and by the absence of an ophthalmology attachment during residency. The table also shows that a large majority did not know the WHO definition of blindness. To the best of our knowledge, the literature contains very few studies that could serve for comparison in this respect. Most of our respondents mentioned more than one ocular sign of vitamin A deficiency (Bitot's spots, xerosis, and keratomalacia), reflecting a moderate to a good level of knowledge that might be explained by the fact that vitamin A deficiency is a common problem in pediatric practice and is likely to be included in their pediatric training curriculum because vitamin A deficiency in children is a public health problem in Ethiopia.

Concerning leukocoria, all but 3 respondents knew that retinoblastoma is a possible cause, but knowledge of cataract as a cause was only moderate and knowledge of ROP as a cause of leukocoria was poor (Table 2). These findings are comparable with those reported in the study carried out in Kenya, in which retinoblastoma was mentioned by $90.60 \%$ and cataract by $74.36 \%$ of the respondents as causes of leukocoria [15]. Regarding knowledge of systemic illnesses associated with congenital cataract, 
Table 3 Practices of treatment and referral of various eye disease cases in children

\begin{tabular}{|c|c|c|}
\hline Question & Respondent's answer(s) & n (\%) \\
\hline \multirow[t]{2}{*}{ Do you do eye examinations on children? $(n=79)$} & Yes & $68(86.1)$ \\
\hline & No & $11(13.9)$ \\
\hline \multirow[t]{3}{*}{ How frequently do you perform eye examinations? $(n=68)$} & Every visit & $29(36.7)$ \\
\hline & When I see an eye problem & $21(26.6)$ \\
\hline & When caregiver complains & $18(22.8)$ \\
\hline \multirow[t]{4}{*}{ Which test do you usually do? $(n=68)$} & Pupillary response & $59(74.7)$ \\
\hline & Ocular motility & $39(49.4)$ \\
\hline & Visual acuity & $31(39.2)$ \\
\hline & Fundus examination & $1(1.3)$ \\
\hline \multirow[t]{5}{*}{ What is/are reasons not to do eye examination? $(n=11)$} & Not adequately trained & $5(6.3)$ \\
\hline & Not my responsibility & $1(1.3)$ \\
\hline & Time-consuming & $1(1.3)$ \\
\hline & Difficult (i.e. children uncooperative) & $2(2.5)$ \\
\hline & I do not know how to examine & $2(2.5)$ \\
\hline \multirow[t]{4}{*}{ How do you manage children with red-eye $(n=79)$} & Give eye drops and refer if no improvement & $39(49.4)$ \\
\hline & Give eye drops & $29(36.7)$ \\
\hline & Give eye drops and refer immediately & $6(7.6)$ \\
\hline & Refer immediately & $5(6.3)$ \\
\hline \multirow[t]{2}{*}{ What do you do for a child who squints? $(n=79)$} & Refer immediately to eye-care worker & $74(93.7)$ \\
\hline & Follow up and refer if it fails to resolve & $5(6.3)$ \\
\hline \multirow[t]{3}{*}{ What do you do for a child in whom you suspect retinoblastoma? $(n=79)$} & Immediately refer to eye-care center & $59(74.7)$ \\
\hline & Order CT-scan & $17(21.5)$ \\
\hline & Order B-scan ultrasonography & $3(3.8)$ \\
\hline What do you do for a child with a congenital cataract? $(n=79)$ & Immediately refer to eye-care worker & $79(100.0)$ \\
\hline \multirow[t]{2}{*}{ What do you do for a child you might suspect of having congenital glaucoma? $(n=79)$} & Refer to eye-care worker immediately & $77(97.5)$ \\
\hline & Give eye drops and follow up & $2(2.5)$ \\
\hline \multirow[t]{4}{*}{ What do you do for a child with congenital tearing? $(n=79)$} & Immediately refer to eye-care worker & $47(59.5)$ \\
\hline & Maintain observation & $23(29.1)$ \\
\hline & Reassure the family & $6(7.6)$ \\
\hline & Give eye drops and send home & $3(3.8)$ \\
\hline
\end{tabular}

we found that such knowledge ranged from good to poor (Table 2): nearly all participants mentioned TORCH infection, while only about a quarter mentioned metabolic disorder, similar to the findings in the Kenya study (94.11 and $28.75 \%$ ) respectively [16].

Poor knowledge about the presentation of congenital glaucoma was indicated by the fact that as many as 55 respondents skipped the question (Table 2). Notably,

Table 4 category of attitude on the Likert Scale $(n=79)$

\begin{tabular}{ll}
\hline Category & n (\%) \\
\hline Positive attitude & $75(94.9 \%$ \\
Neutral attitude & $4(5 / 1 \%)$ \\
Total & 79 \\
\hline
\end{tabular}

buphthalmos, which was included among the questions in this group, was listed by only $17.7 \%$ of respondents, compared to $36.89 \%$ in the Kenya study [15]. The discrepancy can be attributed to the likelihood that this sign is only rarely recognized by parents as a reason to seek health care for their child, as the big eye is considered, in Ethiopian society, to be a beautiful feature. Knowledge of the various causes of tearing in infants was poor, as the mean score of our respondents was only $40.9 \%$. We are not aware of studies that can be cited for comparison.

About the presenting signs of retinoblastoma, Table 2 also shows that knowledge of leukocoria as a presenting symptom was moderate (listed by $70.9 \%$ of our respondents compared to $86.07 \%$ in the Kenya study), while knowledge of proptosis as a presenting symptom was 
poor (57\% compared to $54.10 \%$ in Kenya). The large majority of our respondents listed surgery and chemotherapy as treatment modalities for retinoblastoma (Table 2), indicating a good level of knowledge compared with the Kenya study where $94.40 \%$ of respondents knew that retinoblastoma is a treatable disease [16].

Findings to the clinical practice of Ethiopian pediatricians in dealing with childhood ocular illness (Table 3) were good in that most of the participants reported performing eye examination in children, but were also poor, in that only a few of them do this as a routine part of every child's visit. The practice was moderate for pupillary response testing (which in our study was the test most frequently performed, whereas other authors have reported that the test they most commonly performed in children was VA $[14,16]$; this difference might be attributable to the unavailability of a VA chart in most pediatric departments. Inadequate training was the reason most commonly cited in our study by the few who reported that they do not perform an eye examination. Regarding cases of suspicious retinoblastoma, a majority of respondents (about three quarters) said that they immediately refer the child to an ophthalmologist (reflecting a moderate level of practice), while the rest listed their practice of ordering CT-scan and/or ultrasonography. Further study is needed to identify the characteristics suggestive of retinoblastoma on those imaging modalities.

Overall, the attitude of nearly all of the pediatricians in this study towards the management of childhood eye diseases was positive (Table 4) compared to the study in Kenya [15]. Logistic regression analysis of the association showed no statistically significant association between socio-demographic factors and pediatricians' attitudes to childhood eye morbidities.

\section{Conclusion}

The results of this study demonstrated that even though the participating pediatricians, in general, were found to have moderate or (mainly) poor knowledge and low levels of practice of childhood eye diseases, they exhibited high levels of interest in improving both their knowledge and their practice in aspects such as diagnosis and management of ophthalmic problems and the usage of ophthalmic medications and simple diagnostic instruments. These findings thus demonstrate that centers of academic training in pediatrics and child health need to include courses in pediatric ophthalmology in their curricula for residents. Besides, child-health institutions should ensure that important ophthalmic equipment such as VA charts and direct ophthalmoscopes are available to their health-care workers.

\section{Strength and limitations of the study}

This study is the first to evaluate KAP concerning childhood eye diseases encountered by pediatricians in Ethiopia. Its strength is that it addresses the previously neglected issue of finding ways to overcome childhood blindness, an affliction that continues to profoundly challenge the developing world. The limitations of the study stem from the fact that the data obtained were based on both closed-ended questions which might induce high false-positive, and on self-reported information, a method of investigation which, if used exclusively, is likely to lower the accuracy of the results obtained.

\section{Supplementary Information}

The online version contains supplementary material available at https://doi. org/10.1186/s12886-021-01842-5.

\section{Additional file 1.}

\section{Abbreviations}

KAP: Knowledge, attitude, and practice; NGO: Non-governmental organization; ROP: Retinopathy of prematurity; TORCH: Toxoplasmosis, rubella, cytomegalovirus, herpes simplex; UNICEF: United Nations Children's Fund; VA: Visual acuity; WHO: World Health Organization

\section{Acknowledgments}

We would like to express our thanks to the Ethiopian pediatricians, who interrupted their schedules to participate in the study.

\section{Declarations}

We declare that all the information provided in the manuscript was recorded based on our consensus.

\section{Authors' contributions}

TTR designed the study, collected data, and conducted the analysis, reporting, interpretation, and writing of the manuscript. AAM assisted in the design of the study and data interpretation, and critically reviewed the manuscript. KTD assisted in the design of the study and data interpretation, and critically reviewed the manuscript. IDF assisted in critically reviewing and editing the manuscript. All authors read and approved the final manuscript.

\section{Funding}

Funding for this study was obtained from Jimma University College of Health Sciences, Ethiopia, and was spent on data collection only.

\section{Availability of data and materials \\ The datasets used and analyzed during the current study available from the corresponding author on reasonable request.}

\section{Ethics approval and consent to participate}

Ethical clearance was obtained from the Ethical Review Committee of Jimma University, Ethiopia. All respondents signed their informed consent to participate in the study.

Consent for publication Not applicable.

\section{Competing interests}

The authors declare that they have no competing interests related to the publication of this manuscript.

\section{Author details}

${ }^{1}$ Jimma University, Jimma, Ethiopia. ${ }^{2}$ Goldschleger Eye Institute, Sheba Medical Center, Tel Hashomer, Tel-Aviv University, Tel-Aviv, Israel and the 
International Centre for Eye Health, London School of Hygiene and Tropical Medicine, London, UK.

Received: 28 May 2020 Accepted: 2 February 2021

Published online: 17 February 2021

\section{References}

1. Pring L, Dale N, Tadic V. Copyright $\odot$ the British Psychological Society Attentional processes in young children with congenital visual impairment copyright $\odot$ the British psychological. Society. 2009:311-30.

2. Gilbert C, Bowman R, Malik ANJ. The epidemiology of blindness in children: changing priorities. Community Eye Heal J. 2018;30(100):74-7.

3. Nusrat A, Malik J, Mafwiri M, Gilbert C. Integrating primary eye care into global child health policies. Glob Child Health. 2018;176-180.

4. Gilbert C, Foster A. Childhood blindness in the context of VISION 2020 The Right to Sight. 2001;79(3):227-232.

5. Maida JM, Mathers K, Alley CL. Pediatric ophthalmology in the developing world current opinion in ophthalmology; 2008.

6. WHO. Global initiative for the elimination ofavoidable blindness; 2007. p. 197.

7. Patel DK, Tajunisah I, Gilbert C, Subrayan V. Childhood blindness and severe visual impairment in Malaysia : a nationwide study. Eye [Internet]. 2011; 25(4):436-42 Available from: http://dx.doi.org/10.1038/eye.2011.19.

8. Kong L, Mph MF, Al-samarraie M, Frcophth CG, Steinkuller PG. An update on progress and the changing epidemiology of causes of childhood blindness worldwide. J AAPOS [Internet]. 2017:16(6):501-7 Available from: http://dx. doi.org/10.1016/j.jaapos.2012.09.004.

9. Maida JM, Mathers K, Alley CL. Pediatric ophthalmology in the developing world; 2008

10. Solebo AL, Teoh L, Rahi J. Epidemiology of blindness in children. BMJ. 2017; $1-5$

11. Berhane Y, Worku A, Bejiga A, Adamu L, Alemayehu W, Bedri A, et al. Prevalence and causes of blindness and Low Vision in Ethiopia [Internet]. Ethiop J Health Dev. 2008;21 Available from: http://www.ajol.info/index.php/ ejhd/article/view/10050.

12. Asferaw M, Woodruff G, Gilbert C. Causes of severe visual impairment and blindness in students in schools for the blind in Northwest Ethiopia. BMJ. 2017;1-8.

13. Marcinak JF, Werntz Yount SC. Evaluation of vision screening practices of |llinois pediatricians. Clin Pediatr (Phila). 1995;34(7):353-7.

14. Kemper AR, Clark SJ. Preschool Vision Screening in Pediatric Practices 2015; (April 2006):263-266.

15. Sp W, Marco S, Mm K. Knowledge, attitude and practice of eye diseases in children among paediatricians in Kenya. J Ophthalmol Eastern Central South Afr. 2015;(July):22-26.

16. Bloom BS, Engelhart MD, Furst EJ, Hill WH, Krathwohl DR. The classification of educational goals. Taxon Educ Object. 1956;207:207.

\section{Publisher's Note}

Springer Nature remains neutral with regard to jurisdictional claims in published maps and institutional affiliations.

Ready to submit your research? Choose BMC and benefit from:

- fast, convenient online submission

- thorough peer review by experienced researchers in your field

- rapid publication on acceptance

- support for research data, including large and complex data types

- gold Open Access which fosters wider collaboration and increased citations

- maximum visibility for your research: over $100 \mathrm{M}$ website views per year

At $\mathrm{BMC}$, research is always in progress.

Learn more biomedcentral.com/submissions 